\section{Direct observations of submarine melt and subsurface geometry at a tidewater glacier}

\author{
D. A. Sutherland ${ }^{1 *}$, R. H. Jackson ${ }^{2} \dagger$, C. Kienholz ${ }^{3}$, J. M. Amundson ${ }^{3}$, W. P. Dryer ${ }^{3}$, \\ D. Duncan ${ }^{4}$, E. F. Eidam ${ }^{5}$, R. J. Motyka ${ }^{3,6}$, J. D. Nash ${ }^{2}$
}

Ice loss from the world's glaciers and ice sheets contributes to sea level rise, influences ocean circulation, and affects ecosystem productivity. Ongoing changes in glaciers and ice sheets are driven by submarine melting and iceberg calving from tidewater glacier margins. However, predictions of glacier change largely rest on unconstrained theory for submarine melting. Here, we use repeat multibeam sonar surveys to image a subsurface tidewater glacier face and document a time-variable, three-dimensional geometry linked to melting and calving patterns. Submarine melt rates are high across the entire ice face over both seasons surveyed and increase from spring to summer. The observed melt rates are up to two orders of magnitude greater than predicted by theory, challenging current simulations of ice loss from tidewater glaciers.

I idewater, or marine-terminating, glaciers are the literal ice-ocean boundary in highlatitude environments, connecting the oceans to the continental ice sheets that cover Greenland and Antarctica, as well as smaller ice caps and ice fields such as those found in Alaska. The dynamics of these glaciers influence the rates of ice mass loss and global sea level rise (1,2). Meltwater flux into the oceans also potentially affects global ocean circulation (3), drives locally enhanced ecosystem productivity $(4,5)$, and dominates sediment input into the oceans (6). Because of strong glacier dynamic feedbacks, tidewater glaciers can undergo advance and retreat cycles independent of climate forcing (7) with associated changes in iceberg calving fluxes, subglacial discharge, and submarine melting (8). However, we lack basic measurements on how the submarine termini of these glaciers melt, relying instead on theory (9) constrained by sparse observations from a tidally dominated flow regime at the base of an Antarctic ice shelf (10). Here, we provide direct observations of submarine melt rates from a tidewater glacier using a comprehensive set of ocean, ice, and atmospheric data collected over the 2016-2017 seasons at LeConte Glacier in southeast Alaska.

The need for observational constraints on submarine melting of tidewater glaciers is pressing, as ice loss is accelerating from Antarctica

${ }^{1}$ Department of Earth Sciences, University of Oregon, Eugene, OR 97403, USA. College of Earth, Ocean, and Atmospheric Sciences, Oregon State University, Corvallis, OR 97331, USA. ${ }^{3}$ Department of Natural Sciences, University of Alaska Southeast, Juneau, AK 99801, USA. ${ }^{4}$ Institute for Geophysics, University of Texas at Austin, Austin, TX 78758, USA. ${ }^{5}$ Department of Marine Sciences, University of North Carolina, Chapel Hill, NC 27599, USA. ${ }^{6}$ Geophysical Institute, University of Alaska Fairbanks, Fairbanks, AK 99775, USA. *Corresponding author. Email: dsuth@uoregon.edu †Present address: Department of Marine and Coastal Sciences, Rutgers University, New Brunswick, NJ 08901, USA.
(11, 12), Greenland (13, 14), and mountain glaciers around the globe (15). High-latitude glacier environments continue to experience accelerated warming from both the oceans (16) and the atmosphere (13). A mechanistic parameterization of submarine melt lies at the heart of accurate predictions for the cryosphere. Submarine melt along nearly vertical ice faces influences the terminus position of tidewater glaciers and is also responsible for the input of iceberg meltwater into the ocean (17) and basal melting along the underside of ice shelves (10). Submarine melting enhances subaerial iceberg calving; if submarine melt rates vary vertically because of a dependence on ocean density stratification, ocean temperature, and subglacial discharge, then enhanced calving can extend below the waterline at glacier termini, indirectly affecting glacier stability and the dynamic mass loss of ice sheets (18).

Constraints on basal melting from Antarctic ice shelves come from satellite measurements (12) and from sensors deployed directly on top of ice shelves (19) or in the sub-ice shelf ocean through boreholes drilled through the ice (10). For most tidewater glaciers in Greenland and elsewhere, remote-sensing measurements are unable to resolve the small spatial scales of these glaciers and there is no ice shelf that permits access to the ocean cavity from above. Access to the glacier front is often hindered by icebergs, bergy bits, and sea ice, and during the melt season, subglacial discharge plumes often create strong currents within the near-glacier region (20). Thus, understanding the role of tidewater glaciers within high-latitude environments requires novel observations; to date, no direct measurements of submarine melting at tidewater glacier fronts have been made.

Instead, most recent studies examining iceocean interactions have focused on the subglacial discharge plume, which is driven by glacier runoff that penetrates to depth and exits at the grounding line before upwelling buoyantly along the ice face $(9,20)$. These plumes bring sediment-laden water upward, have turbid surface signatures, and drive substantial fjord circulation $(20,21)$. In addition, the plumes are predicted to enhance melt rates along the adjacent ice face. Numerous studies use pioneering theoretical work that describes the dynamics of these buoyant plumes $(20,22)$. Typically, in these studies, the discharge plume region affects only a narrow swath of the glacier face, usually one to two orders of magnitude narrower than the glacier terminus width (e.g., $100 \mathrm{~m}$ versus 1 to $10 \mathrm{~km}$ ). Ambient melting outside of this enhanced melt region is controlled by local ocean temperatures, stratification, and water velocities $(9,23)$, with melt rates predicted to be two or more orders of magnitude smaller than discharge-driven melt rates, e.g., $0.05 \mathrm{~m}_{\text {day }}{ }^{-1}$ versus $5 \mathrm{~m}$ day $^{-1}(23,24)$. However, several recent studies suggest that ambient melt rates must be higher than predicted and up to the same order of magnitude as discharge-driven melt $(23,25,26)$. This discrepancy in predicted versus inferred ambient melt rates is important to resolve with direct observations as we move beyond providing annual snapshots of ice sheet mass loss $(11,14)$ and freshwater input to the oceans (27) and work to predict glacier change at ice sheet margins across a broad range of temporal and spatial scales.

Without direct measurements of submarine melt, we must rely on indirect methods to infer submarine melt, either with buoyant plume theory (9) or an oceanographic flux-gate method $(21,28)$. The advantage of buoyant plume theory is its simplicity and reliance only on far-field ocean measurements. However, it assumes knowledge of subglacial conduit geometry, the magnitude of discharge, untested empirical constants (29), and the portions of the ice face that undergo ambient melt and discharge-enhanced melt. By contrast, the flux-gate method exploits heat, salt, and mass conservation to constrain freshwater fluxes in the near-terminus region using far-field data alone. The advantage of the flux-gate method is the avoidance of needing any knowledge of the dynamic near-glacier environment. However, it requires dense ocean measurements, assumes perfect closure, and often neglects storage terms in the heat, salt, and mass budgets. Also, the method estimates the total meltwater flux instead of a localized melt rate (28), and thus cannot provide information on where melt occurs spatially. Finally, the method may have high uncertainties when fjord circulation is weak or time variable (28)

To address the lack of direct submarine melt observations, we conducted two field campaigns (29) at LeConte Glacier $\left(56.80^{\circ} \mathrm{N}, 132.45^{\circ} \mathrm{W}\right)$, a $477-\mathrm{km}^{2}$ tidewater glacier that drains from the Stikine Icefield in southeast Alaska (Fig. 1). Ice flow velocities reach up to $\sim 25 \mathrm{~m} \mathrm{day}^{-1}$ near the glacier terminus $(30,31)$, which, if near steady state, must be balanced by both calving and submarine melting (21). Proglacial LeConte 
Bay is a narrow fjord (1 to $1.5 \mathrm{~km}$ wide), with a mean depth of $\sim 170 \mathrm{~m}$. Two vessels collected hydrographic (i.e., temperature and salinity profiles) and water velocity measurements concurrently in the near-glacier fjord, with ocean operations spanning 9 to 16 August 2016 and 6 to 14 May 2017. One vessel made repeat multibeam sonar surveys of the glacier front (Table 1). We concurrently operated time-lapse cameras, a terrestrial scanning radar, and a meteorolog- ical station from a ridge adjacent to the glacier terminus, and collected glacier mass balance data to calibrate a glacier runoff model (figs. S1 and S2) (29).

Environmental conditions varied seasonally, with ocean temperatures from $6^{\circ}$ to $7.5^{\circ} \mathrm{C}$ in August and $1^{\circ}$ to $4.5^{\circ} \mathrm{C}$ in May (fig. S3). Modeled subglacial discharge, based on weather observations, was high in August, ranging from 100 to $350 \mathrm{~m}^{3} \mathrm{~s}^{-1}$ during relatively warm and wet weather, and low in May, ranging from 20 to $100 \mathrm{~m}^{3} \mathrm{~s}^{-1}$ during relatively cold and dry weather (fig. S2), with little evidence of subglacial runoff mixing in May (fig. S3). More icebergs covered the near-terminus area in May than in August, in addition to relatively weaker water velocities in May (fig. S5). However, both ocean transect and time-lapse camera data show subglacial discharge plumes in the same southern location in both seasons (figs. S4 and S5).

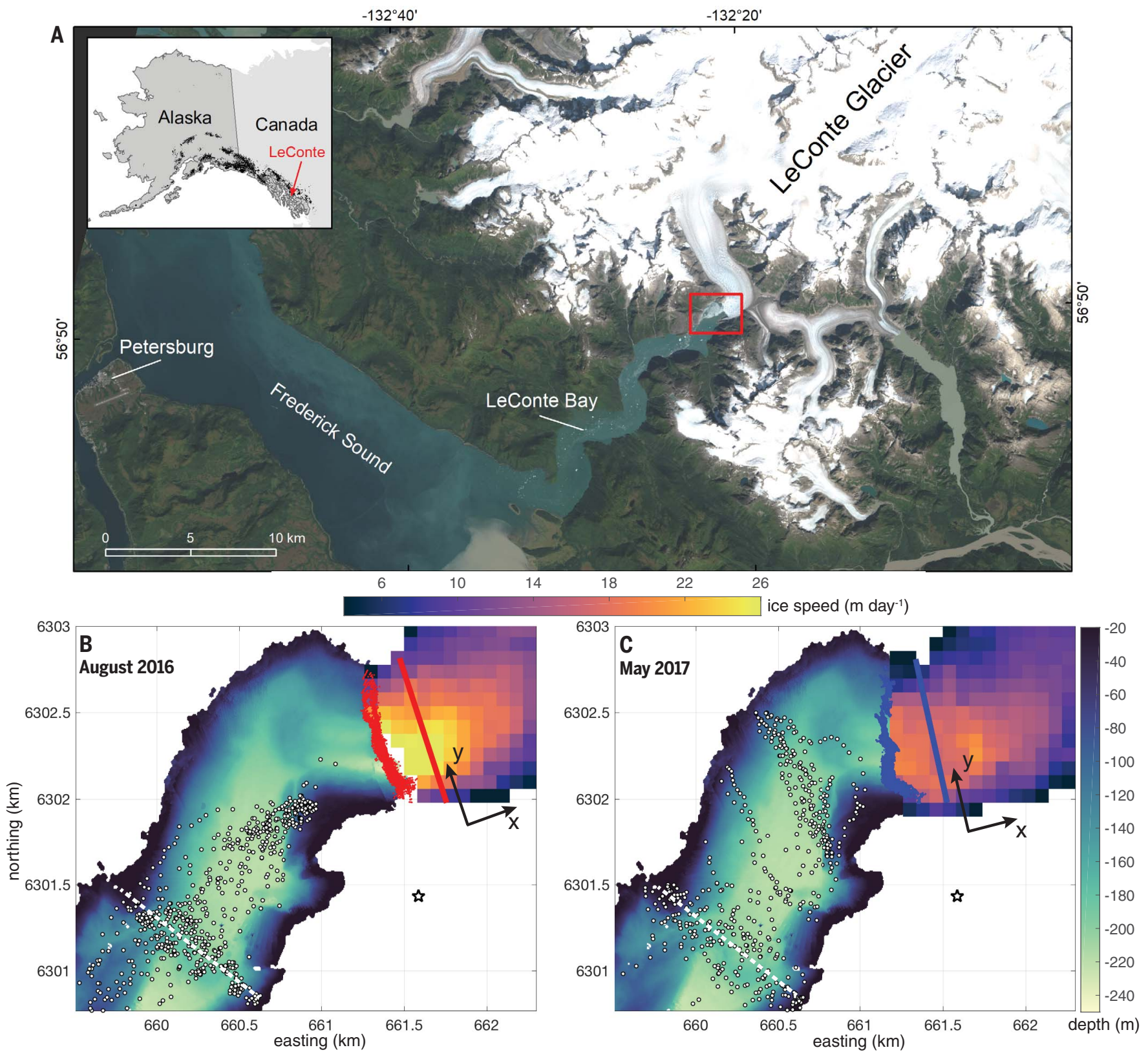

Fig. 1. Physical setting and data collection overview. (A) Map of LeConte Glacier at the head of LeConte Bay. Red box delineates the enlarged region shown in (B) and (C). Inset shows location of LeConte Glacier in southeast Alaska. (B) Terminus points from multibeam data in August 2016 (red dots) on top of other data collected during the same time period, including average ice speed from terrestrial radar located on 
We collected six nearly complete multibeam sonar images of the subsurface ice face in August 2016 and five in May 2017 (Table 1). The glacier has a deep grounding line centered over two troughs in the middle of the fjord (Fig. 2). The entire subsurface ice face is nonplanar, with regions of undercutting and overcutting that extend over the entire water column, in addition to localized slope changes. Extensive retreat and calving were observed on the southern terminus in both seasons (Fig. 2 and fig. S9). However, the vertical slope of the glacier changed between seasons. We observed a $45^{\circ}$ undercut near where the plume was emerging in August (Fig. 2C), whereas in May, when discharge was considerably lower, the same region exhibited an ice foot that extended $>50 \mathrm{~m}$ seaward of the surface expression of the terminus (Fig. 2E). Overall, the late summer (August) ice face was more undercut than the spring (May) ice face (Table 1). Compared with a vertical, two-dimensional underwater surface area, accounting for the undulating shape of the ice increases the area by $\sim 35 \%$ in both August and May (Table 1).

Submarine melt rates are computed by differencing multibeam point clouds while taking into account glacier geometry and motion (29). These directly estimated submarine melt rates vary significantly across the two seasons, with overall mean melt rates equal to $5.1 \pm$ $0.6 \mathrm{~m} \mathrm{day}^{-1}$ in August versus $1.4 \pm 0.1 \mathrm{~m} \mathrm{day}^{-1}$ in May (Fig. 3). These melt rates imply that, on average, $\sim 22 \%$ of the ice flux in August is ac- counted for by submarine melting (the rest is lost by calving), whereas only $8 \%$ of the ice flux in May is attributed to melt. These estimates are lower than the $\sim 50 \%$ previously inferred from ocean flux-gate methods (21); however, our numbers may be biased low because our method excludes actively calving areas where melt rates might be relatively high (such as the southern side where the discharge plume is active). By contrast, previous flux-gate-derived values may be biased high because they include iceberg melt and the surveys tend to occur during daytime, when discharge and melting are above average.

We found a significant depth variation in the submarine melt rate across the terminus (Fig. 3). In August, melt rates are relatively high $\left(8 \mathrm{~m} \mathrm{day}^{-1}\right)$ at the surface and decrease with depth to a minimum, before increasing again deeper in the water column to $>8 \mathrm{~m} \mathrm{day}^{-1}$. The high melt rates at depth occur only over the deep troughs (Fig. 2) with relatively high uncertainty. Nonetheless, the vertically varying melt rate would imply undercutting of the terminus at depth and overcutting in the upper $20 \mathrm{~m}$. In May, the situation changes, with the lowest melt rates $\left(<0.5 \mathrm{~m} \mathrm{day}^{-1}\right)$ found at depth and the highest melt rates $\left(2.1 \mathrm{~m} \mathrm{day}^{-1}\right)$ found near the surface (Fig. 3). The observed ice front shapes (Fig. 2) show patterns of overcutting and undercutting that align with those implied by the melt-rate profiles (Fig. 3 and fig. S12), suggesting that the variability in submarine melt rates with depth can explain the large-scale terminus shape. The exception is the shallow south-
Table 1. Overview of multibeam sonar data and subsurface terminus shape. Coverage is the percentage of the terminus face captured during each pass. Subsurface area $\left(10^{3} \mathrm{~m}^{2}\right)$ is calculated for each pass accounting for spatial heterogeneities: where no data exist, we assume a vertical face and a planar $x-y$ area. Mesh size is $10 \mathrm{~m}$ by $10 \mathrm{~m}$. For comparison, planar $x-y$ areas are reported for each season (i.e., no sloping face). The percentage undercut encompasses portions of the glacier face with angles from vertical $>3^{\circ}$ (overcut is $<-3^{\circ}$ ), and the remaining percentage is indistinguishable from vertical because of multibeam data uncertainties $\left(-3^{\circ}\right.$ to $\left.3^{\circ}\right)$. Bold indicates lack of terrestrial radar data for that pass.

\begin{tabular}{|c|c|c|c|c|}
\hline & Pass & Coverage (\%) & Area $\left(10^{3} \mathrm{~m}^{2}\right)$ & Undercut/Overcut (\%) \\
\hline \multicolumn{5}{|l|}{ August 2016} \\
\hline 10-Aug 14:24 & 1 & 82 & 147.7 & $23 / 70$ \\
\hline 12-Aug 06:33 & 2 & 81 & 141.9 & $27 / 66$ \\
\hline 13-Aug 00:39 & 3 & 85 & 151.1 & $38 / 52$ \\
\hline 14-Aug 04:37 & 4 & 62 & 157.7 & $43 / 48$ \\
\hline 14-Aug 19:39 & 5 & 76 & 162.9 & $37 / 53$ \\
\hline 15-Aug 02:15 & 6 & 69 & 144.3 & $32 / 56$ \\
\hline Mean & & $76 \%$ & $\begin{array}{c}150.9 \\
(x-y \text { area: } 112 \%)\end{array}$ & $\begin{array}{c}33 / 58 \\
\text { (vertical 9\%) }\end{array}$ \\
\hline \multicolumn{5}{|l|}{ May 2017} \\
\hline 10-May 03:14 & 1 & 59 & 130.9 & $24 / 66$ \\
\hline 10-May 22:06 & 2 & 73 & 140.5 & $26 / 64$ \\
\hline 10-May 23:41 & 3 & 88 & 146.7 & $25 / 65$ \\
\hline 11-May 02:53 & 4 & 72 & 146.6 & $25 / 65$ \\
\hline 12-May 00:40 & 5 & 46 & 135.6 & $22 / 74$ \\
\hline Mean & & $67 \%$ & $\begin{array}{c}140.8 \\
(x-y \text { area: } 104 \%)\end{array}$ & $\begin{array}{c}24 / 69 \\
\text { (vertical } 7 \% \text { ) }\end{array}$ \\
\hline
\end{tabular}

ern region in August that is severely undercut (Fig. 2C) yet shows relatively high surface melt rates (fig. S12), which implies that calving sets the terminus shape there.

More detailed spatial and temporal patterns in melt are difficult to resolve because of uncertainties and the limited observations in the across-glacier direction (fig. S12). Only the southern terminus region in May exhibited significantly higher melt than the rest of the terminus (fig. S12), coinciding with an overcut region in that season (Fig. 2). In August, the shapes of the melt-rate profiles were similar across the glacier face (fig. S12), with a suggestion of larger overall melt rates on the southern side of the terminus, corresponding to the location of the observed subglacial discharge plume (fig. S5).

These direct estimates of submarine melt are much higher than ambient melt estimates calculated with existing theory (29), which range from 0.02 to $0.07 \mathrm{~m} \mathrm{day}^{-1}$ in August and 0.01 to $0.07 \mathrm{~m} \mathrm{day}^{-1}$ in May (Fig. 3 and fig. S13). In the discharge plume region, theory broadly matches the observed magnitudes in August, when discharge is relatively high (Fig. 3A). In both August and May, theory predicts higher melt rates in the discharge plume region over a range of plausible discharge magnitudes and conduit geometries (Fig. 3), yet these enhanced melt rates only occur over a limited spatial extent. Averaged over the total ice face area, melt rates predicted by buoyant plume theory (i.e., ambient plus discharge plume-enhanced) are much lower and not significantly different across the seasons, ranging from $0.9 \pm 0.4 \mathrm{~m} \mathrm{day}^{-1}$ in August to $0.5 \pm$ $0.3 \mathrm{~m} \mathrm{day}^{-1}$ in May. Although the vertical dependence of melting is predicted by theory to be similar in both seasons (increasing with depth), the observed structure has the opposite variability between seasons (Fig. 3). Additionally, theory predicts large differences in melt rates (two orders of magnitude) between discharge-driven melt and ambient melting, but the observations show high melt rates of similar magnitude across the entire terminus. Thus, parameterizations developed from plume theory would lead to inaccurate subsurface morphology changes (i.e., overcutting or undercutting) and unrealistic differences in melt rates between regions of ambient melting and discharge-driven melting.

Oceanographic measurements input into the flux-gate method (29) result in relatively high average submarine melt rates (Fig. 3) in both August $\left(9.0 \pm 1.8 \mathrm{~m} \mathrm{day}^{-1}\right)$ and May $\left(4.3 \pm 2.5 \mathrm{~m} \mathrm{day}^{-1}\right)$ based on available transects (table S4). These melt rates come from dividing the calculated meltwater flux by the total subsurface ice front area and include iceberg melt. Generally, the fluxgate results have closer correspondence with the multibeam-derived measurements compared with plume theory-derived values during periods of strong discharge, suggesting that ocean measurements are a viable way to infer total freshwater influx from the glacier (table S4) when (i) spatial information on melting processes is not needed and (ii) strong discharge plumes are present (e.g., August). 
Fig. 2. Subsurface terminus geometry from August and May multibeam data.

(A) Map view of average horizontal terminus shape in distinct vertical layers (colors) for August 2016, when multibeam uncertainties were $\pm 4 \mathrm{~m}$. (B) Point cloud data (colored dots with black contours) from August 2016 pass number 3 overlaid on gridded seafloor bathymetry (colored mesh). View direction is toward the glacier from elevation $=30^{\circ}$ and azimuth $=-105^{\circ}$. Colored line segments show across-glacier location of vertical profiles in (C). (C) Vertical profiles of the subsurface terminus shown in (B) at select across-glacier locations (color corresponds to location). (D) Same as in (B), but for May 2017 pass number 3. (E) Same as in (C), but for May 2017, when multibeam uncertainties were $\pm 2 \mathrm{~m}$. (F) Same as in (A), but for May 2017.

Fig. 3. Comparison of submarine melt rates from three independent methods.

(A) Red shading indicates the mean multibeam-derived melt rates perpendicular to the ice face for August 2016; red markers show the mean melt in distinct depth layers, including uncertainty (horizontal bars). Dark gray shading shows the depth-dependent area-averaged melt rate from buoyant plume theory (BPT), combining ambient melt (solid lines, barely distinguishable from zero) across the ice face with locally enhanced dischargedriven melt (dashed line) starting at the deepest grounding line depth (red star). The discharge-driven melt rates cover a range (thin dashed lines) of subglacial discharge conditions and geometries. The range (mean \pm uncertainty) of melt rates derived from the flux-gate method are shown in light gray shading. (B) Same as (A), but for May 2017 over a reduced $x$-axis scale, with blue colors used for multibeam-derived melt rates and the location of the deepest grounding line depth.
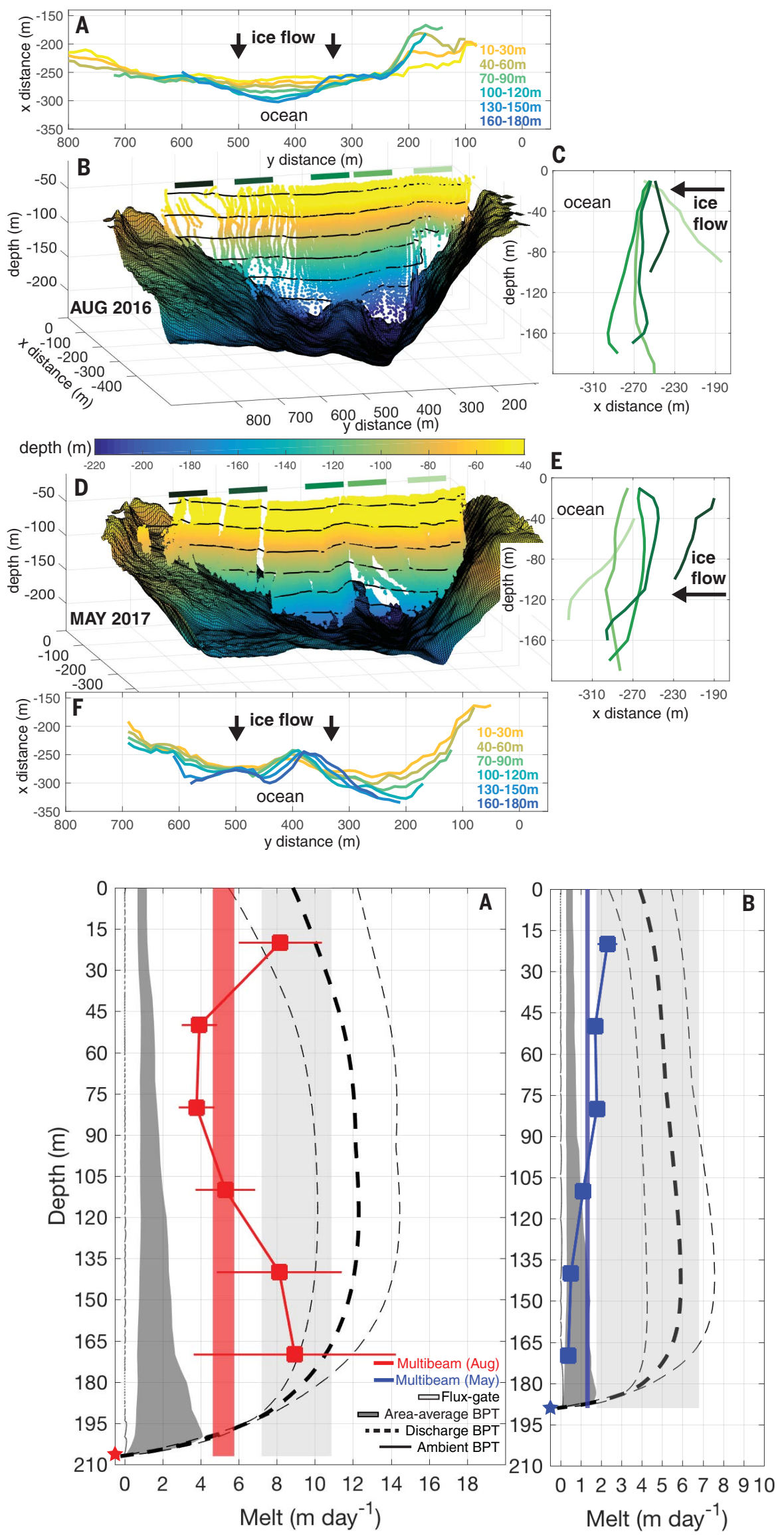
Our results confirm the high melt rates suggested by several recent studies $(23,25,26)$. The multibeam-derived melt rates go beyond model-based inferences, providing direct observations of submarine melting at a tidewater glacier that are critically needed to constrain theory and develop parameterizations. The observed melting patterns show a changing terminus shape over the seasons that does not follow from present-day melt parameterizations $(32,33)$. If submarine melting does indeed influence iceberg calving and the subsequent glacier dynamic response (18), then accurately predicting where in space and time melting occurs is critical. Submarine melting does not appear to be a simple function of temperature and subglacial discharge but may also vary with the vigor of other near-terminus circulation patterns (25). The processes that enhance near-terminus circulation are either directly related to the glacier terminus itself (30) (e.g., iceberg calving, plume discharge) or by other fjord processes (e.g., tidal currents, internal waves), suggesting that complex feedbacks exist that are completely absent from current simulations of submarine glacier mass loss.

\section{REFERENCES AND NOTES}

1. F. M. Nick, A. Vieli, I. M. Howat, I. Joughin, Nat. Geosci. 2. 110-114 (2009)

2. I. Joughin, R. B. Alley, D. M. Holland, Science 338, 1172-1176 (2012).
3. C. W. Böning, E. Behrens, A. Biastoch, K. Getzlaff, J. L. Bamber, Nat. Geosci. 9, 523-527 (2016).

4. C. Lydersen et al., J. Mar. Syst. 129, 452-471 (2014).

5. M. J. Hopwood et al., Nat. Commun. 9, 3256 (2018).

6. I. Overeem et al., Nat. Geosci. 10, 859-863 (2017).

7. D. Brinkerhoff, M. Truffer, A. Aschwanden, Nat. Commun. 8, 90 (2017)

8. J. M. Amundson, D. Carroll, J. Geophys. Res. Earth Surf. 123 66-79 (2018).

9. A. Jenkins, J. Phys. Oceanogr. 41, 2279-2294 (2011).

10. A. Jenkins, K. W. Nicholls, H. F. J. Corr, J. Phys. Oceanogr. 40, 2298-2312 (2010)

11. E. Rignot et al., Proc. Natl. Acad. Sci. U.S.A. 116, 1095-1103 (2019).

12. A. Shepherd et al., Nature 558, 219-222 (2018).

13. M. R. van den Broeke et al., Cryosphere 10, 1933-1946 (2016).

14. M. Bevis et al., Proc. Natl. Acad. Sci. U.S.A. 116, 1934-1939 (2019). 15. V. Radić, R. Hock, Nat. Geosci. 4, 91-94 (2011).

16. L. Cheng, J. Abraham, Z. Hausfather, K. E. Trenberth, Science 363, 128-129 (2019)

17. T. Moon et al., Nat. Geosci. 11, 49-54 (2018).

18. Y. Ma, J. N. Bassis, J. Geophys. Res. Earth Surf. 124, 334-346 (2019)

19. P. E. D. Davis et al., J. Geophys. Res. Oceans $123,8655-8669$ (2018)

20. F. Straneo, C. Cenedese, Ann. Rev. Mar. Sci. 7, 89-112 (2015)

21. R. J. Motyka, L. Hunter, K. A. Echelmeyer, C. Connor, Ann. Glaciol. 36, 57-65 (2003).

22. Y. Xu, E. Rignot, I. Fenty, D. Menemenlis, M. M. Flexas, Geophys. Res. Lett. 40, 4648-4653 (2013)

23. M. J. Fried et al., Geophys. Res. Lett. 42, 9328-9336 (2015).

24. S. J. Magorrian, A. J. Wells, J. Geophys. Res. Oceans 121 , 4670-4696 (2016)

25. D. A. Slater et al., Geophys. Res. Lett. 45, 12350-12358 (2018).

26. T. J. W. Wagner et al., Cryosphere 13, 911-925 (2019).

27. J. L. Bamber et al., J. Geophys. Res. Oceans 123, 1827-1837 (2018)
28. R. H. Jackson, F. Straneo, J. Phys. Oceanogr. 46, 2735-2768 (2016).

29. See materials and methods in the supplementary materials.

30. C. Kienholz et al., J. Glaciol. 65, 195-211 (2019).

31. J. Amundson et al., Collaborative research: impact of subglacial discharge on turbulent plume dynamics and ocean-glacier heat and mass transfer, Southeast Alaska, 2016-2017, Arctic Data Center (2017); https://doi.org/10.18739/A22G44.

32. E. Rignot et al., Geophys. Res. Lett. 43, 6374-6382 (2016). 33. A. Luckman et al., Nat. Commun. 6, 8566 (2015).

\section{ACKNOWLEDGMENTS}

We thank the crew of the MV Steller and MV Pelican, Petersburg High School, and the U.S. Forest Service. Funding: This work was supported by National Science Foundation grants OPP-1503910, 1504191, 1504288, and 1504521. Author contributions: D.A.S., J.M.A., R.J.M., and J.D.N. designed the study: D.A.S., D.D., and E.F.E. led the multibeam collection and analysis; J.M.A., C.K., W.P.D, and R.J.M. led the glacier observations; J.D.N. and R.H.J. led the near-terminus ocean observations and plume theory calculations; R.J.M. and R.H.J. led the flux gate analysis: all authors edited and contributed to the manuscript. Competing interests: The authors declare no competing interests. Data and materials availability: All processed ocean data [conductivity, temperature, and depth (CTD), acoustic Doppler current profiler (ADCP), multibeam] have been archived at the National Centers for Environmental Information (NCEI) (https://accession.nodc. noaa.gov/0189574). All of the glacier data have been archived at the Arctic Data Center (31).

\section{SUPPLEMENTARY MATERIALS}

science.sciencemag.org/content/365/6451/369/suppl/DC1 Materials and Methods

Figs. S1 to S13

Tables S1 to S4

References (34-48)

21 March 2019; accepted 27 June 2019

10.1126/science.aax3528 


\section{Science}

\section{Direct observations of submarine melt and subsurface geometry at a tidewater glacier}

D. A. Sutherland, R. H. Jackson, C. Kienholz, J. M. Amundson, W. P. Dryer, D. Duncan, E. F. Eidam, R. J. Motyka and J. D. Nash

Science 365 (6451), 369-374.

DOI: $10.1126 /$ science.aax3528

\section{Underwater melting}

How fast does warm ocean water melt glaciers that terminate in the sea? That question is central to understanding how fast ice sheets may lose mass, and thus how fast sea level will rise, in response to global warming, but there are few data about the process. Sutherland et al. used repeat multibeam sonar surveys to observe an Alaskan subsurface tidewater glacier face to create a time series of its melting and calving patterns. They observed melt rates up to a hundred times larger than those predicted by theory, observations that compel us to reevaluate predictions of such ice loss.

Science, this issue p. 369

ARTICLE TOOLS

SUPPLEMENTARY MATERIALS

REFERENCES

PERMISSIONS http://science.sciencemag.org/content/365/6451/369

http://science.sciencemag.org/content/suppl/2019/07/24/365.6451.369.DC1

This article cites 44 articles, 4 of which you can access for free http://science.sciencemag.org/content/365/6451/369\#BIBL

http://www.sciencemag.org/help/reprints-and-permissions

Use of this article is subject to the Terms of Service

Science (print ISSN 0036-8075; online ISSN 1095-9203) is published by the American Association for the Advancement of Science, 1200 New York Avenue NW, Washington, DC 20005. 2017 (C) The Authors, some rights reserved; exclusive licensee American Association for the Advancement of Science. No claim to original U.S. Government Works. The title Science is a registered trademark of AAAS. 